\title{
Liver transplantation in Egypt from West to East
}

This article was published in the following Dove Press journal:

Transplant Research and Risk Management

2 April 2010

Number of times this article has been viewed

\section{Galal H El-Gazzaz' \\ Azza $\mathrm{H}$ El-Elemi ${ }^{2}$ \\ 'Department of General Surgery, ${ }^{2}$ Department of Forensic Medicine and Ethics, Suez Canal University, Ismailia, Egypt}

Correspondence: Galal El-Gazzaz

Department of Colorectal Surgery A30, Cleveland Clinic Foundation, Cleveland, Ohio-44195, USA

Tel + I 2164443103

Email elgazzg@ccf.org
Background: Egyptian patients with end-stage liver disease need to seek whole cadaveric liver transplantation (CLT) abroad. We studied the outcome of Egyptian patients who underwent CLT in China.

Methods: Between 2004-2006, 22 patients who underwent CLT in China and attended two liver surgery outpatient clinics in Egypt for follow-up were included in the study. Demographic, preoperative, postoperative, and follow-up data after coming back from China were reviewed.

Results: For 22 patients of median age 48 years (30-62) and with BMI $27.5 \pm 6.2$, the median follow-up was 23.5 months (range 1-48); 18 patients were males. Hepatitis C (HCV)-cirrhosis alone or with schistosomiasis was the main indication for CLT $(n=12)$; Hepatitis B (HBV)cirrhosis was the indication for transplantation in two patients, $\mathrm{HCV}$-cirrhosis with hepatocellular carcinoma (HCC) in six, HBV-cirrhosis with HCC in one, and both HBV- and HCV-related cirrhosis with HCC in another. There were eight deaths, one as a result of primary nonfunction, one because of postoperative bleeding, two because of recurrent $\mathrm{HCV}$, and four because of recurrent HCC. Overall survival at one and three years was $68.5 \%$ and $64 \%$, respectively, and $50 \%$ and $37.5 \%$ for HCC patients, respectively, while three-year survival was $80 \%$ for hepatitis patients. Twelve patients (54\%) developed complications. Biliary complications occurred in $45 \%$ of cases.

Conclusion: CLT tourism to China raises serious concerns regarding selection criteria and ethical issues. Furthermore, the negative impact of this practice on the successful setting up of LT programs in Egypt must be addressed carefully. In Egypt efforts should be directed to get legalization for CLT.

Keywords: hepatitis B, hepatitis C, end-stage liver disease, transplantation, Egypt, China

\section{Introduction}

Egypt is a heavily populated country, with a strikingly high hepatitis $\mathrm{C}$ virus (HCV) infection prevalence of $26 \%$. $^{1,2}$ The high prevalence of chronic liver diseases in Egypt has led to increasing numbers of Egyptian patients suffering from end-stage liver disease. Liver transplantation (LT) is the most effective treatment for end-stage liver disease and selected primary hepatic malignancies. To date, cadaveric organ donation has been illegal in Egypt, therefore Egyptian patients with end-stage liver disease continue to seek whole cadaveric organ transplantation abroad. In the last decade and early years of this decade most patients have sought a new liver in Europe and the US. However, this is not a feasible option for most Egyptian patients.

In Western countries, the average waiting time for an overseas patient to receive a cadaveric graft is between 18 and 24 months. ${ }^{3-5}$ There is significant patient mortality 
during this long waiting period. Also, the increasing costs of organ transplantation in Western countries and bad quality grafts donated to overseas patients had increased the impact of the results. Ironically, all these problems led to the speedy launch of successful living donor liver transplantation (LDLT) programs in Egypt. ${ }^{5}$ However, these programs have been faced by high procedural costs because they are mainly private-based. Also commercialism and problems with unsuitable donors force Egyptian patients deprived of cadaveric organ donation in their homeland to turn to other Eastern countries, China in particular, where the cost of transplantation is lower compared with the West and even compared with living donor LT in Egypt. Ethical considerations including prioritization on waiting lists, the search for suitable donors, and quality of organs transplanted are the main obstacles facing patients seeking transplantation abroad.

The number of cadaveric LTs undertaken in China has been increasing in recent years ${ }^{4,6,7}$ and this treatment is available to patients from Egypt and other countries. Thus, the option of going to China for cadaveric LT has become attractive for a number of patients in the last few years. The purpose of this study was to evaluate outcomes in 22 Egyptian patients who underwent cadaveric LT in China and to address the relevant medical and ethical concerns.

\section{Methods}

In Egypt, 22 patients who underwent cadaveric LT in China attended the liver surgery outpatient clinics at Suez Canal University Hospital and Naser Institute in Cairo between March 2004 and December 2006 for follow-up and immunosuppressive therapy. Most of patients has had their transplants in Tianjin $(n=16)$, and the remainder in Guangzhou $(n=4)$ and Shanghai $(\mathrm{n}=2)$.

Patient records were reviewed retrospectively for preoperative assessment and evaluation data before traveling to China, and available information and reports provided by the hospitals in China were reviewed. Full assessments were performed, including history, physical examination, blood tests (complete blood count, clotting profile, liver and renal function tests, blood glucose level, hepatitis status, and blood levels of immunosuppressants), chest X-ray, and cholangiography if a T-tube was in situ. The types and dosages of immunosuppressive therapy were reviewed and data concerning follow-up after coming back from China were also retrospectively reviewed.

\section{Statistical analysis}

Kaplan-Meier analysis using Statistical Package for Social Science Software (version 8; SPSS Inc., Chicago, IL) was used to obtain a post-liver transplant survival curve.

\section{Results}

Twenty-two Egyptian patients underwent cadaveric LT in China. The male to female ratio was 18:4 and median age was 48 (30-62 years, Table 1). The main indication for LT was HCV cirrhosis alone or with schistosomiasis $(n=12)$. HBV cirrhosis was the indication for LT in two patients, $\mathrm{HCV}$ cirrhosis with $\mathrm{HCC}$ in six patients, HBV cirrhosis with $\mathrm{HCC}$ in one patient, and $\mathrm{HBV}+\mathrm{HCV}$ cirrhosis with $\mathrm{HCC}$ in another patient. Of the 22 patients, five $(22.5 \%)$ had advanced HCC and were not accepted by any center in Egypt for living related LT. Seven patients were evaluated for living related LT but none of their potential donors was considered suitable. The remaining 10 patients refused the option of having living related LT in Egypt and opted from the outset to have a whole liver graft in China.

The median duration of follow-up was 23.5 months (range $<1-48$ months). Overall survival at one and three years was $68.5 \%$ and 64\%, respectively (Figure 1). For HCC patients, the survival rate was $50 \%$ and $37.5 \%$, respectively (Figure 2). For hepatitis patients, the three-year survival rate was $80 \%$ (Figure 2).

Twelve patients (54\%) developed complications after returning from Egypt. Biliary complications were encountered in 10 patients $(45 \%)$; this included simple bile leak in five patients, all of whom responded to nonsurgical management. Three patients had ischemic bile duct strictures; this was defined as a nonanastomotic intrahepatic biliary lesion with either two or more sites of stricture formation and/or biliary dilatation, or multiple intrahepatic fluid collections or abscesses (Figure 3). One patient died, the other two still have problems with different maneuvers of drainage and stenting. The remaining two patients had anastomotic biliary obstruction which required biliary reconstruction. One patient had portal vein thrombosis and the other developed intra-abdominal abscess requiring percutaneous drainage.

There were eight deaths. Two patients had died in China (one due to primary nonfunction and the second as a result of postoperative bleeding). Two patients died in Egypt from recurrent $\mathrm{HCV}$ five and eight months after transplantation, one as a result of increased liver enzymes and and the other because of liver cell failure with encephalopathy. Both of these patients were admitted to ICU and died a short time 
Table I Patient characteristics

\begin{tabular}{|c|c|c|c|c|c|}
\hline Patient no. & Sex/age & Indication for LT & Date & Follow-up & Current patient status \\
\hline I & $M / 5 I$ & $\mathrm{HCV}$ cirrhosis + HCC & Mar 2004 & $<1$ & Died in hospital \\
\hline 2 & $M / 4 I$ & HCV cirrhosis & Jun 2004 & $<1$ & Died in hospital \\
\hline 3 & $M / 60$ & HCV cirrhosis & Sep 2004 & 48 & Alive \\
\hline 4 & $F / 53$ & $\mathrm{HCV}$ cirrhosis + HCC & Aug 2004 & 18 & Died (recurrent HCC) \\
\hline 5 & $M / 6 I$ & HCV cirrhosis & Oct 2004 & 40 & Alive \\
\hline 6 & $M / 47$ & $\begin{array}{l}\text { HCV seeking cadaveric LT } \\
\text { cirrhosis }\end{array}$ & Nov 2004 & 8 & Died (recurrent HCV) \\
\hline 7 & $M / 44$ & Hepatitis C cirrhosis & Dec 2004 & 37 & Alive \\
\hline 8 & $M / 46$ & $\mathrm{HCV}$ cirrhosis + HCC & Jan 2005 & 42 & Alive \\
\hline 9 & $M / 54$ & HCV cirrhosis & Feb 2005 & 38 & Alive \\
\hline 10 & $\mathrm{~F} / 57$ & $\mathrm{HCV}$ cirrhosis + HCC & Apr 2005 & 8 & Died (recurrent HCC) \\
\hline II & $\mathrm{F} / 47$ & HCV cirrhosis & Jun 2005 & 35 & Alive \\
\hline 12 & $M / 49$ & $\mathrm{HCV}$ cirrhosis + HCC & Jul 2005 & 30 & Alive \\
\hline 13 & $M / 4 I$ & HCV cirrhosis & Sep 2005 & 42 & Alive \\
\hline 14 & $\mathrm{~F} / 52$ & HCV cirrhosis & Sep 2005 & 5 & Died (recurrent HCV) \\
\hline 15 & $M / 43$ & HCV cirrhosis & Aug 2005 & 25 & Alive \\
\hline 16 & $M / 40$ & $\mathrm{HCV}$ cirrhosis + HCC & Oct 2005 & 10 & Died (recurrent HCC) \\
\hline 17 & $M / 39$ & $\mathrm{HCV}+\mathrm{B}$ cirrhosis $+\mathrm{HCC}$ & Oct 2005 & 24 & Alive \\
\hline 18 & $M / 45$ & HCV cirrhosis & Jan 2006 & 30 & Alive \\
\hline 19 & $M / 43$ & HCV cirrhosis & Mar 2006 & 22 & Alive \\
\hline 20 & $M / 43$ & $\mathrm{HCV}$ cirrhosis + HCC & May 2006 & 5 & Died (recurrent HCC) \\
\hline 21 & $M / 43$ & HCV cirrhosis & Jul 2006 & 28 & Alive \\
\hline 22 & $M / 43$ & HCV cirrhosis & Oct 2006 & 24 & Alive \\
\hline
\end{tabular}

Abbreviations: $\mathrm{HBV}$, hepatitis B virus; $\mathrm{HCV}$, hepatitis C virus; $\mathrm{HCC}$, hepatocellular carcinoma; $\mathrm{LT}$, liver transplant.

after admission. The other four patients died in Egypt from recurrent $\mathrm{HCC}$.

Four patients with HCV-related liver cirrhosis and HCC developed recurrent disease with bilateral pulmonary and bone metastases and died in Egypt a short time after LT.

The current immunosuppression protocol consists of a double regimen of a steroid and tacrolimus. The steroid was rapidly tapered off with the aim of tacrolimus monotherapy.

\section{Discussion}

In Egypt, many factors have contributed to the recent marked increase in the number of patients turning to China for whole liver organ transplantation. The ever increasing numbers of patients who are in desperate need of LT because of the failure of the Egyptian government to legalize cadaveric organ donation has created a very difficult situation in the healthcare system in Egypt. Furthermore the cost of cadaveric LT in Western countries is very high, with overseas patients having a long waiting time for a cadaveric graft, which may reach 18 to 24 months. ${ }^{3-5}$ There is significant mortality during this long waiting period and the quality of grafts donated to overseas patients tends to be suboptimal. ${ }^{3}$ Another major concern about live donation in Egypt is the likelihood of organ donation for money, given Egypt's high poverty rate. Also a number of potential live donors are rejected in Egypt because of the high incidence of chronic liver diseases in that country. ${ }^{5}$ Costs are another legitimate concern in Egypt; it has been debated whether few patients should benefit from LT when there are many others who do not receive medication for common diseases, and who should absorb the high costs of this expensive procedure. Currently, most LDLT procedures have been performed in private medical centers, and patients have covered the costs either entirely or partially. At present, without adequate health insurance systems, LDLT is only offered to Egyptian patients who can afford it. ${ }^{5}$

Shorter waiting lists, good quality of organs, avoidance of the need to search for suitable living related donors, and avoidance of exposure of a loved one to the risk of a major operation are additional factors contributing to Egyptian patients who can afford the costs seeking cadaveric LT in Eastern countries. $^{8-10}$ 


\section{Survival function}

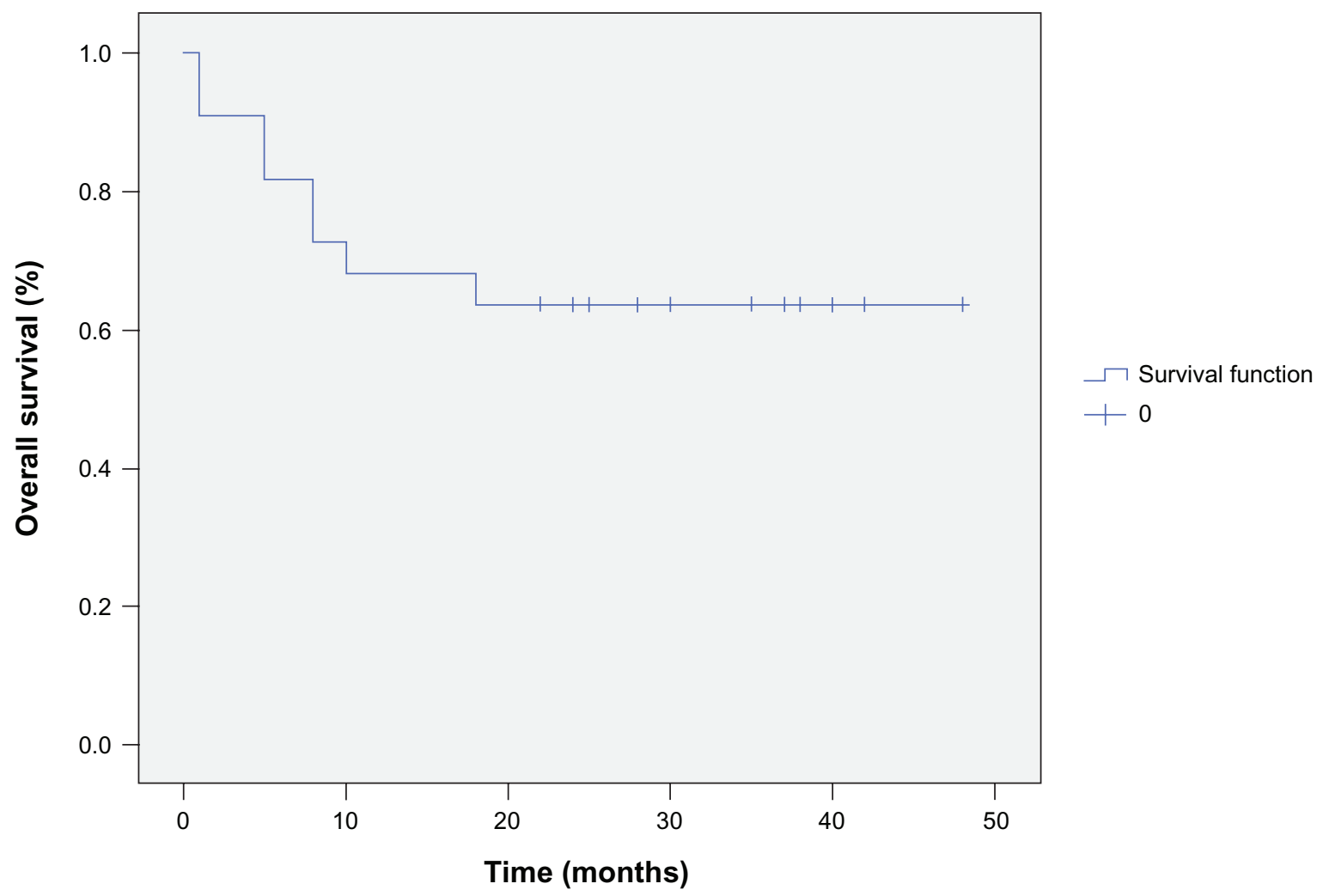

Figure I Overall survival of Egyptian patients transplanted in China.

During the same period, the number of patients who underwent living related LT in Egypt are getting small as most of the centers did less number of patients during the last year than previous years, ${ }^{3-8}$ and this also raises concerns regarding the negative impact of LT in China on the growing LDLT program in Egypt and on the volume of cases done every year in these centers.

Although LT is the most effective treatment for end-stage liver diseases, it is a highly complex procedure, and is associated with significant morbidity and mortality for both donors and recipients. ${ }^{9-11}$ Complications that occur after LT also have a significant impact on resource utilization and costs. ${ }^{12}$

This study has reported the outcome for 22 patients who received cadaveric LT in China. It is worth emphasizing that this is a multicenter review; therefore, the following results do not reflect the performance of any particular center. Patients electing to travel to China for LT may represent a selected group of high-risk patients. It is not appropriate to view the outcomes for these 22 patients as representative of the results achieved with LT in China overall. Unfortunately, publications in China are not well indexed in the international literature and, until recently, few papers concerning LT in
China have been published..$^{8-11,13}$ It is therefore difficult to access data on a large case series of LT as a comparative standard.

Advanced HCC is a contraindication for LT because of the high risk of recurrence. For selected patients with a small HCC that is not resectable because of location or underlying cirrhosis, a five-year survival rate of approximately $70 \%$ can be achieved after LT. ${ }^{14,15}$ However, in China, LT in cases with HCC seem to have no medical or ethical restriction regarding the outcome. Here we have to emphasise that from the eight patients we identified who were transplanted for HCC, six were rejected for LDLT by different centers in Egypt due to advanced HCC, so they traveled to China to get their LT there. The outcome after transplantation in those patients was poor, with one-year and three-year survival rates of $50 \%$ and $37.5 \%$, respectively, which is comparable with other series. ${ }^{14,15}$ These patients highlight the unethical differences in selection criteria for transplantation between hospitals in China and other institutions.

After transplantation in China, the recipients returned to Egypt after 2-4 weeks for follow-up care. The information accompanying them was not always comprehensive. 


\section{Survival functions}

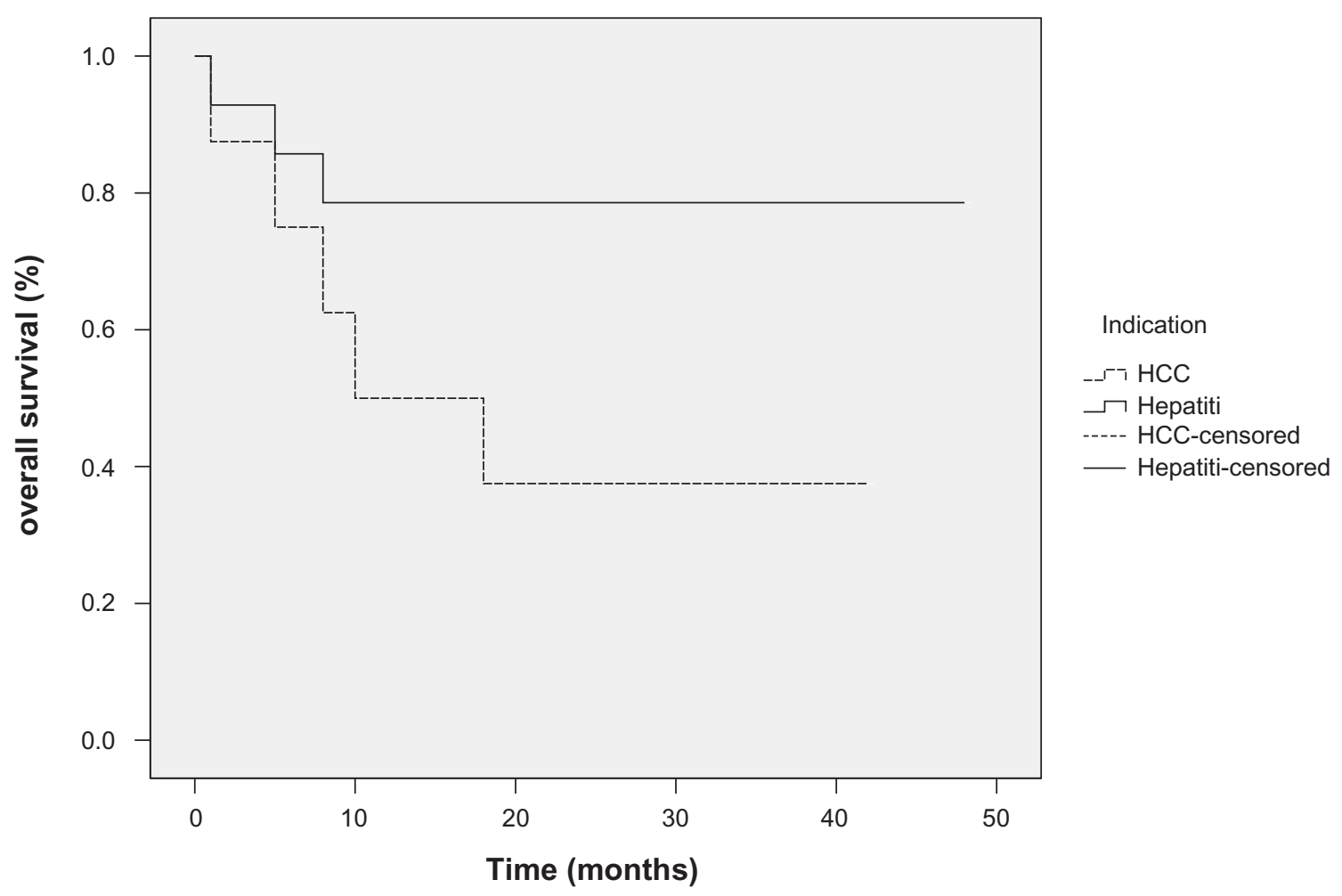

Figure 2 Survival Egyptian patients with hepatitis and HCC transplanted in China.

Information regarding the status of the donor and the pathology of the explanted liver, which are crucial for subsequent management and follow-up, and for indicating possible complications, were often missing. This added to difficulties in the clinical management of this group of patients.

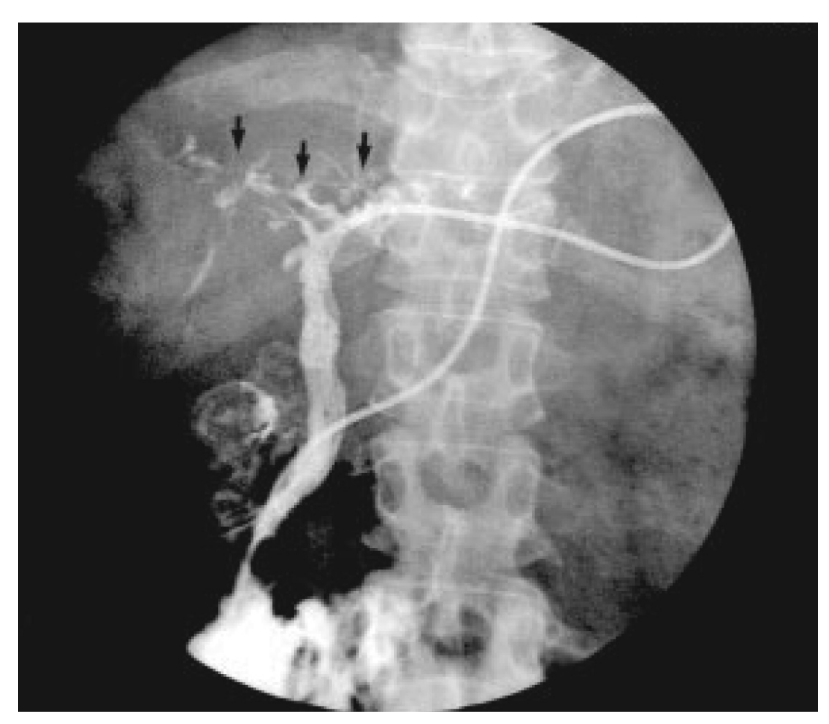

Figure 3 T-tube cholangiogram shows features of diffuse ischemic biliary stricture (arrows).
Biliary complications occurred in $45 \%$ of patients in this study. Biliary complications are a continuing concern in LT, occurring in $8 \%$ to $15 \%$ of cases, with a mortality rate of $10 \%{ }^{16-18}$ Diffuse biliary stricture occurring in three patients in this series could have resulted from ischemia as a result of hepatic artery thrombosis, extended graft preservation time, warm ischemic time, and $\mathrm{ABO}$ incompatibility and rejection. ${ }^{17}$ It is likely that the occurrence of diffuse ischemic bile duct stricture in these cases was due to warm ischemic injury to the donor liver during harvesting because all hepatic arteries in these three patients were patent on Doppler ultrasound. Information on the process of donor liver graft preservation, as well as cold and warm ischemic time during these patients' procedures was not available. Diffuse ischemic bile duct stricture triggers the need for re-transplantation. Bile leakage around the T-tube or after its removal is related to inadequate development of the fibrous tract along the course of the T-tube tract, probably caused by impairment of fibrogenesis under steroid immunosuppression. ${ }^{18}$

It is inappropriate to make generalizations based only on the outcome for the 22 patients reviewed. Patients who decide to seek treatment in China should be aware of the potential risks they may encounter. However, clinicians considering 
referral of patients to China for consideration of cadaveric LT should also be aware of the potential medical risks, as well as the resource implications of appropriate patient follow-up on their return to Egypt.

Finally, we express our serious concerns regarding selection criteria and the ethical aspects of cadaveric liver transplant tourism to China which influence the patient-care decision-making and the outcome of the process. Also, the negative impact this practice has on starting LT programs in Egypt must be addressed carefully from the medical and ethical perspectives of both donors and recipients. In Egypt efforts should be directed towards legalization for cadaveric organ donation because this can resolve the problem of unfair distribution of healthcare services among patients seeking LT. We also have to work hard to overcome the problem of high costs of LDLT and to adopt firm regulation concerning organ donation for money.

\section{Acknowledgement}

This paper was presented as a poster at the Pan-Arabic Liver Transplantation Society meeeting in Riyadh, Saudi Arabia, in March 2007. The authors report no conflicts of interest in this work.

\section{References}

1. El-Zayadi A, Selim O, Rafik M, El-Haddad S. Prevalence of hepatitis $\mathrm{C}$ virus among non-A, non-B-related chronic liver disease in Egypt. J Hepatol. 1992 Mar;14(2-3):416-417.

2. Habib M, Mohamed MK, Abdel-Aziz F, et al. Hepatitis C virus infection in a community in the Nile Delta: Risk factors for seropositivity. Hepatology. 2001;33:248-253.
3. Khalaf H, Farag S, El-Hussainy E. Long-term follow-up after liver transplantation in Egyptians transplanted abroad. Saudi Med J. 2004;25:1931-1934.

4. Wong ACC, Lo CM, Liu CL. Outcome for Hong Kong residents undergoing cadaveric liver transplantation in mainland China. Hong Kong Med J. 2003;9:165-170.

5. Khalaf H, El-Meteini M, El-Sefi T, et al. Evolution of living donor liver transplantation in Egypt Saudi Med J. 2005;26:1394-1397.

6. Huang J. Ethical and legalisative perspectives on liver transplantation in the People's Republic of China. Liver Transpl. 2007;13: 193-196.

7. Rakela J, Fung J. Liver transplantation in China. Liver Transpl. 2007;13:182.

8. El-Meteini M, Fayez A, Fathy M, et al. Living related liver transplantation in Egypt: An emerging program. Transplant Proc. 2003;35: 2783-2786.

9. Peng S. Improving the level of liver transplantation in China. Zhonghua Yi Xue Za Zhi. 2001;81:1089-1090.

10. Chen S, Qiu F. Progress in the study of organ transplantation in China. Zhonghua Yi Xue Za Zhi. 1998;78:912-913.

11. Xia SS. Organ transplantation in China: Retrospect and prospect. Chin Med J (Engl). 1992;105:430-432.

12. Brown RS Jr, Ascher NL, Lake JR, et al. The impact of surgical complications after liver transplantation on resource utilization. Arch Surg. 1997;132:1098-1103.

13. Li S, Stratta RJ, Langnas AN, Wood RP, Marujo W, Shaw BW Jr. Diffuse biliary tract injury after orthotopic liver transplantation. Am J Surg. 1992;64:536-540.

14. Mazzaferro V, Regalia E, Doci R, et al. Liver transplantation for the treatment of small hepatocellular carcinomas in patients with cirrhosis. N Engl J Med. 1996;334:693-699.

15. Figueras J, Ibanez L, Ramos E, et al. Selection criteria for liver transplantation in early-stage hepatocellular carcinoma with cirrhosis: Results of a multicenter study. Liver Transpl. 2001;7:877-883.

16. O’Connor TP, Lewis WD, Jenkins RL. Biliary tract complications after liver transplantation. Arch Surg. 1995;130:312-317.

17. Sanchez-Urdazpal L, Gores GJ, Ward EM, et al. Diagnostic features and clinical outcome of ischemic-type biliary complications after liver transplantation. Hepatology. 1993;17:605-609.

18. Shuhart MC, Kowdley KV, McVicar JP, et al. Predictors of bile leaks after T-tube removal in orthotopic liver transplant recipients. Liver Transpl Surg. 1998;4:62-70.
Transplant Research and Risk Management

\section{Publish your work in this journal}

Transplant Research and Risk Management is an international, peerreviewed open access journal focusing on all aspects of transplantation and risk management to achieve optimal outcomes in the recipient improving survival and quality of life. The journal welcomes submitted papers covering original research, basic science, clinical studies,

\section{Dovepress}

reviews \& evaluations, guidelines, expert opinion and commentary, case reports and extended reports. The manuscript management system is completely online and includes a very quick and fair peer-review system, which is all easy to use. Visit http://www.dovepress.com/ testimonials.php to read real quotes from published authors. 